\title{
Software for ESL
}

Lynn McAlpine

Up to now, microcomputer software has tended to focus on providing drill and practice to the relative exclusion of other applications. Since there are relatively few software programmes (other than drill and practice) designed specifically for use in the teaching and learning of English as a second language, it might be appropriate to look at the many other educational software programmes available in order to consider their potential as useful ESL learning tools.

In what follows, the author presents a rationale for looking at software other than that designed specifically for ESL, suggests criteria for use in evaluating such software, and, finally, lists some general software which seems to have potential ESL applications.

\section{Rationale}

It seems to be a generally agreed point in the literature (e.g., Wyatt, 1984; Higgins and Johns, 1984; Ahmed, Corbett, Rogers and Sussex, 1985 ) that there is not much microcomputer software developed specifically for learners of English as a second language. In addition, what little exists is often not good quality and, thus, calls into question (in the teacher's mind at least) the efficacy of microcomputer use in ESL learning.

If one looks at the research data on the issue of effectiveness, at the moment, the jury seems to be out. For example, Ahmed et al (1985) conclude that there is sufficient data to show the effectiveness of microcomputer uses in the drill and practice mode, but not sufficient evidence in other modes, such as problem solving and simulations. (This latter statement is probably a reflection of the scarcity of ESL software other than that designed for drill and practice.) On the other hand, Wyatt (1984) reports mixed results. He suggests there is not sufficient quantitative evidence to draw any conclusions about the effectiveness of microcomputers in ESL; nevertheless, he adds that the qualitative reports, for example, verbal reports from users, have been positive. Finally, Higgins and Johns (1984) among others, suggest we cannot know how effective microcomputers can be in ESL until we begin to experiment with as many different forms of software as possible, not just drill and practice.

This point is well taken. So, I would like to explore it a bit further by using the trichotomy described in Taylor (1980). Taylor classifies com- 
puter applications in education into three categories: tutor, tool and tutee.

In the tutor mode, the computer is used as a means of delivering instruction. The most common examples of this category are probably drill and practice and tests.

The second category in Taylor's classification system is the tool mode. In this mode, the software allows the users to enter whatever content they wish and to manipulate this content easily and efficiently in order to accomplish a specific task. The most common form of the tool mode is probably the word processor which permits the user to revise a written product very easily. The tool mode differs from the other two modes in that its primary function is to facilitate the users' ability to do something that they could do without the computer but less quickly and effectively.

In the third mode, that of tutee, the user instructs the computer to do something; programming in other words. Many computer users never operate in this mode, although it can be fun to try programming even at an elementary level. However, even at this level, the experience can be overwhelming and confusing (Canale and Barker, 1986). The fact is that serious programming is a highly complex skill which takes time to acquire. For those interested in learning how to programme their own ESL software using BASIC, see Kenning and Kenning (1983) and Higgins and Johns (1984).

Higgins and Johns (1984) and, more recently, Canale and Barker (1986) have suggested looking at modes other than the tutor. If one takes this advice, one is, for the moment at least, forced to go outside the software specifically designed for ESL. And, as Agor (1986) suggests, this can be advantageous: suddenly, anything written in English is fair game.

In the rest of this paper, criteria are suggested for evaluating the potential of non-ESL software for ESL use, and examples of software which seem to hold promise for ESL learners are described.

\section{Evaluation Criteria}

As soon as one goes outside the subject area of ESL, one is faced with a plethora of choice which is overwhelming. I would suggest one way to limit this choice is to set as the principle evaluation criterion that software be in the tool mode. The rationale for this suggestion being that since in the tool mode the user inserts the content, this type of software has the greatest flexibility and adaptability to the student's ESL ability, and at the same time, enough structure to avoid the confusion students may experience when using software in the tutee mode. This is not to suggest that tutee mode software might not be useful in some ESL classrooms, rather that tool software seems to have wider ESL applications.

Once a piece of software has been identified as being in the tool mode, it needs to be judged as to its adequacy for general non-ESL use. There 
are many forms of general software evaluation offered in the literature (cf. Wright 1985). These vary widely from the connoisseur model which requires the reviewer to summarize his findings in terms of three or four graded scales, e.g., York Educational Software Evaluation Scales, to the technical model with a yes/no checklist of thirty or forty items. One can also find something in between these two extremes, e.g., Clement (1983). In looking at these forms, one gets the impression there is little consensus as to the criteria to be used. Nevertheless, it is evident that certain features, e.g., documentation, and technical adequacy, recur consistently.

If a piece of software meets most of the general criteria you have set, that is, if you feel it is a good piece of software, then criteria relating to its potential for application in the ESL classroom need to be considered.

The level of the language used in the instructions is a primary concern. There are two aspects to this criterion: difficulty of vocabulary and complexity of syntax. Could any ESL student use it, or only one at an intermediate or advanced level?

The second criterion in terms of ESL appropriateness is the potential for wide application. The student user is going to invest time in learning how to use the programme, time which may be extensive no matter how simple the instructions are because comprehending the instructions involves using a second language. (In fact, the reading involved in learning how to use the software is an ESL lesson in itself.) Thus, the wider the application possibilities the greater the value in investing the learning time.

\section{Examples of Tool Software for Use in ESL}

Described below are some software programmes for the Apple IIe which meet the evaluation criteria outlined previously, that is, each programme is in the tool mode, is a good piece of general software, and satisfies the specific ESL criteria mentioned.

\section{Crossword Magic}

Crossword Magic is a crossword puzzle generator that can be used by students (or teachers) to create a variety of sizes of puzzle using any words the user wishes. It's easy and quick to use. The user types in each word and is offered a variety of possible placements within the puzzle as it presently exists. If a word won't fit at the time it is entered, the word is saved and can be added later. When the user has inserted all the words he wants, he creates the clues. The programme automatically numbers the vertical and horizontal words and clues. The puzzle can be saved in progress; it can be printed (nice graphics); it can be played on the screen and saved when partly done. This programme could be used at all levels because the difficulty of the puzzle can be controlled. Students could use 
it to make puzzles for other students, or for themselves in order to practice and test their knowledge and spelling of words they have difficulty with. Since the user enters them, the complexity of the clues (both vocabulary and syntax) could be increased as the student becomes more advanced in his use of English. The puzzle could even be used as a different test format.

\section{M-ss-ng L-nks}

The 1987 version of $M$-ss-ng $L-n k s$ generates modified cloze exercises (texts in which certain words are removed) and allows variations in "missing links" from missing vowels or consonants to missing every nth word. Again, it is easy and quick to use. The user types in any text (some samples are provided) and then chooses what variation on a cloze he wants. In attempting to do the exercise, the user has the ability to set the number of guesses allowed, to set the number of tries for each player if more than one person is playing, and to save the work and continue the exercise later. Again, this programme seems to have a lot of potential ESL applications both for the teacher and the learner. It can be used as a game in which students' knowledge of English syntax is developed or as a test in which their knowledge is assessed; it can be varied in difficulty depending on the linguistic ability of the learner, both in terms of the readability level of the texts inserted and in terms of the difficulty of the task. Or, if the vowel and consonant variations of the programme are used, students can check their knowledge of English spelling conventions.

\section{The Print Shop}

The Print Shop is a generator of signs, banners, cards and letterhead. It is extremely easy to use and quickly produces professional looking work. Work can be saved though usually it is not difficult to complete the task in progress within fifteen minutes. The major drawback to this programme is that printing can take a long time . . . a problem if the printer is being shared. This programme is useful because it provides a means for beginning students to create professional looking written products when their vocabulary and syntax are still very limited. For example, the programme could be used to prepare signs with simple instructions, or to prepare and send personalized cards.

\section{Ten Clues}

Ten Clues is a guessing game generator in which the user chooses a word and then enters clues which he thinks will help others to guess the word. Other users play the game trying to maintain as high a score as possible (each game begins with a score of eighty). It is easy to prepare a game, and games can be saved. This game allows the ESL user to 
manipulate the language at the appropriate level of ability without concern for syntax at the sentence level as clues are single words or phrases. It can be used at all levels, but students would probably most enjoy playing the games prepared by others at a similar level.

\section{Race the Clock}

Race the Clock is a generator of concentration games played against time. The user creates games by inserting matched pairs of words, verbs, nouns, adjectives, etc., and the programme presents a grid in which the pairs of words are scattered at random. The number of pairs of words presented can be controlled by the user. The rules are just the same as in the card game concentration. The player begins by "turning up" a square; he then tries to find the word that goes with it. If the second square chosen does not go with the first word, both squares are turned over and the player begins again. There is a time limit which can be adjusted by the user. Because of this time limit, the game can be played by just one user, even the creator of the game. It should be noted though, that this programme cannot be used without reference to the documentation. Again, this game can be used at all levels; it could be used to practice opposites, past tense, prepositions, in other words, any aspect of language that can be conceptualized as a dichotomy.

\section{Sensible Grammar}

Sensible Grammar is a punctuation, cliché and faulty phrase checker that can be used with many Apple-compatible word processor programmes. What it does is proofread your text looking for any of the punctuation, word and phrase errors included in its lists. It will highlight these words, suggest alternatives and leave the user to make the decision. Users can add their own personalized lists to the checker. The major drawback is the time it takes to start using the programme. You really need to do the tutorial that is a part of the software and use the extensive documentation to get a good understanding of how to use the programme. The ESL students who master this piece of software have an invaluable tool at their command. No matter what their writing level in English, they can become their own editors taking on responsibility for proofreading before the teacher ever sees their writing. They can begin to see patterns in the types of errors they make and can create their own word and expression lists including in them the kinds of errors that they make regularly.

\section{Conclusion}

An attempt has been made in this paper to make explicit some evaluation criteria to use in judging the potential of non-ESL software for use in the 
learning of ESL. Specifically, it was suggested that the primary criterion be whether the software is in the tool mode. It is hoped this presentation will encourage others involved in ESL to take a serious look at the learning potential of all non-ESL tool software.

\section{REFERENCES}

Agor, B. (1986). Non-ESL software for second language development. Special Issue on CALL of the TESOL Newsletter, XX:1, 15-17.

Ahmed, K., Corbett, G., Rogers, M., \& Sussex, R. (1985). Computers, language learning and language teaching. London: Cambridge University Press.

Canale, M., \& Barker, G. (1986). How creative language teachers are using microcomputers. Special lssue on CALL of the TESOL Newsletter, XX:1, 1-3.

Clement, F.J. (1983). How an average person can test a software programme. Performance and Instruction Journal, June, 27-28.

Higgins, J., \& Johns, T. (1984). Computers in language learning. London: Collins ELT.

Kenning, M.J., \& Kenning, M.M. (1983). An introduction to computer assisted language learning. Oxford: Oxford University Press.

Taylor, R.P. (Ed.). (1980). The computer in the school: Tutor, tool, tutee. New York: Columbia University Teachers' Press.

Wright, E.B. (1985). The computer: A tool for the teacher. Belmont, Ca.: Wadsworth, Inc.

Wyatt, D.H. (1984). Computers and English as a second language. Orlando: Harcourt, Brace and Jovanovich, Inc.

\section{Software Cited}

Crossword Magic. (1985). Northbrook, Ill.: Mindscape, Inc.

M-ss-ng L-nks. (1987). Pleasantville, N.Y.: Sunburst Communications.

The Print Shop. (1984). Broderbund Software, Inc.

Race the Clock. (1984). Stoneham, Ma.: Mindplay, Methods and Solutions, Inc.

Sensible Grammar. (1985). Birmingham, Mi.: Sensible Software, Inc.

Ten Clues. (1986). Pleasantville, N.Y.: Sunburst Communications, Inc.

\section{THE AUTHOR}

Lynn McAlpine has considerable experience as a teacher of ESL adult students, as a materials designer and as a teacher trainer. Her interest in ESL computer applications stems from a concern with finding ways to enable ESL students to have more control over their learning experiences. 